\title{
Infertile Partners' Coping Strategies Are Interrelated - Implications for Targeted Psychological Counseling
}

\author{
Wechselbeziehungen bei den Bewältigungsstrategien unfruchtbarer \\ Partner - Implikationen für eine zielgerichtete psychologische Beratung
}

Authors

L. Volmer ${ }^{1}$, S. Rösner ${ }^{2}$, B. Toth ${ }^{2}$, T. Strowitzki ${ }^{2}$, T. Wischmann ${ }^{1}$

Affiliations

1 Institut für Medizinische Psychologie, Zentrum für Psychosoziale Medizin, Heidelberg, Germany

2 Universitätsfrauenklinik, Abteilung für Gynäkologische Endokrinologie und Fertilitätsstörungen, Heidelberg, Germany

Key words

infertility, couples, coping, APIM, concordance

$$
\begin{aligned}
& \text { Schlüsselwörter } \\
& \text { Übereinstimmung } \\
& \text { received 11.8.2016 } \\
& \text { revised 9.10.2016 } \\
& \text { accepted 16.10.2016 }
\end{aligned}
$$$$
\text { Unfruchtbarkeit, Paare, Bewältigungsstrategie, APIM, }
$$

\section{Bibliography}

DOI http://dx.doi.org/10.1055/s-0042-119200

Geburtsh Frauenheilk 2017; 77: 52-58 @ Georg Thieme Verlag KG Stuttgart · New York | ISSN 0016-5751

\section{Correspondence}

Léa Volmer

Institut für Medizinische Psychologie, Zentrum für Psychosoziale Medizin

Bergheimer Straße 20, 69115 Heidelberg, Germany lea.volmer@laposte.net

\section{ABSTRACT}

Background Infertility patients often have high stress levels which, in some cases, represent a risk of developing depression or anxiety. The SCREENIVF questionnaire is a validated tool to evaluate such risks. Some coping strategies have been shown to be correlated with infertile couples' levels of stress. Determining which strategies are correlated with higher levels of risk for depression or anxiety could be useful to offer targeted psychological counseling to reduce the risk of depression or anxiety.

Materials and Methods A total of 296 women and men who attended the Fertility Center at Heidelberg University Hospital completed the SCREENIVF questionnaire and the COMPI coping scales. Data were analyzed first on an individual basis and focused on the couple, using the Actor Partner Interdependence Model.

Results On an individual level, active avoidance coping was positively correlated with a higher risk of depression or anxiety in women, while meaning-based coping was negatively correlated with risk in men.
When the results of couples were viewed together, women and men using active avoidance coping exhibited higher risk scores as individuals (actor effect), as did their partners (partner effect). Women who used meaning-based coping had positive actor and partner effects. Women using active-confronting coping had a negative partner effect (higher risk score for men).

Conclusions These findings indicate that some coping strategies may have a protective effect while others may increase the risk of emotional maladjustment in infertile couples. Further analysis of coping strategies could help to identify new counseling approaches for infertile patients.

\section{ZUSAMMENFASSUNG}

Hintergrund Viele unfruchtbare Patienten leiden unter einer höheren Stressbelastung, was in manchen Fällen das Risiko erhöht, eine Depression oder Angststörung zu entwickeln. Der SCREENIVF-Fragebogen stellt ein validiertes Instrument zur Evaluierung dieser Risiken dar. Es hat sich gezeigt, dass manche Bewältigungsstrategien mit der Stressbelastung von unfruchtbaren Paaren korrelieren. Für die betroffenen Patienten könnte es nützlich sein, die Strategien, die mit einem höheren Risiko für Depression oder Angststörung einhergehen, zu identifizieren. Diese Patienten könnten dann gezielt eine psychologische Beratung erhalten, um ihr Risiko für Depression oder Angststörung zu mindern.

Material und Methoden 296 Frauen und Männern, die im Kinderwunschzentrum des Universitätsklinikums Heidelberg vorstellig wurden, haben den SCREENIVF-Fragebogen und die COMPI-Bewältigungsskala ausgefüllt. Die Daten wurden zunächst individuell analysiert und wurden danach mithilfe des Akteur-Partner-Interdependenz-Modells mit den Daten des Partners verglichen.

Ergebnisse Auf individueller Ebene war bei den Frauen eine aktive Vermeidungsstrategie positiv mit einem höheren Risiko für Depression und Ängstlichkeit korreliert; bei Männern hingegen korrelierte eine sinngebende Bewältigung negativ mit dem Risiko, eine Depression oder Angststörung zu entwickeln. Wurden die individuellen Ergebnisse eines Paares zusammen betrachtet, zeigte sich, dass Frauen und Männer, die eine aktive Vermeidungsstrategie verfolgten, höhere Risikowerte aufwiesen, sowohl einzeln betrachtet (Akteureffekt) als auch als Partner (Partnereffekt). Bei Frauen, die eine sinngebende Bewältigungsstrategie verwendeten, waren Akteur- und Partnereffekte positiv. Bei Frauen, die eine aktiv konfrontative Strategie pflegten, war der Partnereffekt negativ (Risikowerte waren bei Männern höher).

Schlussfolgerungen Diese Ergebnisse weisen darauf hin, dass bestimmte Bewältigungsstrategien eine schützende Wirkung haben können, während andere Strategien das Risiko einer emotionalen Fehlanpassung bei unfruchtbaren Paaren erhöhen können. Eine weitergehende Analyse von Bewältigungsstrategien könnte dazu beitragen, dass neue Beratungsmethoden bei unfruchtbaren Paaren angewendet werden. 


\section{Introduction}

In 2012, more than 640000 assisted reproductive technology (ART) cycles were reported to the European Society of Human Reproduction and Embryology (ESHRE), an increase of $4 \%$ compared to the previous year [1]. More than 140000 children in Europe were born after ART in 2012. Infertility itself is considered a lowcontrol stressor for couples [2], and treatment for infertility and its uncertain outcome add to these couples' burden. The impact of this stressor has been studied in detail over the past decades [3-5]. Before the start of IVF treatment, patients were not more depressed than the general population or matched controls, and the evidence on whether patients are more anxious before the start of their first IVF cycle than the general population is inconsistent. According to recent guidelines [6], 1 in 4 women and 1 in 10 men had a depressive disorder, and one in 7 women and 1 in 20 men had an anxiety disorder after receiving the pregnancy test for their IVF/ICSI treatment. The fact that the experience of and the medical treatment for infertility can lead to emotional maladjustment makes it essential to detect patients at risk for depression or anxiety. The SCREENIVF questionnaire is a validated tool to identify patients at risk [7]; the ESHRE guidelines advise using it before the start of every new ART treatment cycle [6]. Patients found to be at risk can benefit from psychological counseling, even more so if targeted strategies could reduce the risk of emotional maladjustment [8].

The capacity to adapt to infertility-related stress depends on the woman's and her partner's coping strategies [9, 10]. Coping strategies used by infertile couples are categorized into 4 groups: active-confronting (e.g., asking friends and relatives for advice), active-avoidance (not sharing feelings; avoiding pregnant women), passive-avoidance (hoping for a miracle; believing that waiting is the only solution) and meaning-based coping (e.g., believing that the experience has led to great personal growth or that the marriage has evolved in a good way) [11].

Which strategies correlate positively with a risk of depression or anxiety and thus should be avoided? Which ones reduce the risks and could be used for targeted counseling? Studies have shown that active-avoidance coping had a negative effect, whereas meaning-based coping could have a positive effect on emotional adjustment [12].

The aim of this study was to analyze whether the findings of previous studies into beneficial coping strategies could be confirmed in order to determine potential ways of optimizing psychological counseling.

\section{Material and Methods}

\section{Setting and questionnaires}

Between July 2014 and July 2015, all couples who attended the Fertility Center of Heidelberg University Hospital were informed about the study. Persons willing to participate were given additional information about the study, an informed consent sheet and asked to complete three questionnaires:
- SCREENIVF [7]: This is a questionnaire validated to screen fertility patients at risk for depression or anxiety. The questionnaire covers 5 areas of risk. There are 5 items on state anxiety and 5 on trait anxiety (e.g., worrying too much about things that are not really important; higher scores mean an increased risk) taken from the short version of the State and Trait Anxiety Inventory (STAI) [13]; 7 items on depression (items measuring sadness or self-depreciation; higher scores mean an increased risk) from the short Beck Depression Inventory [14]; 5 items on social support (presence of someone who offers comfort or talking; lower scores mean an increased risk); and 12 items on cognition about fertility problems (having learned to live with and accept fertility problems), with 6 for helplessness (higher scores mean an increased risk) and 6 for acceptance (lower scores mean an increased risk). Each item is answered using a four-level Likert scale. The score for each risk factor is then calculated by adding up the answers for each item. A patient is considered at risk when at least one of the scores exceeds or is below a clinically relevant cut-off: 24 or above for the STAI short version; 4 or above for the BDI items; 13 or less for social support; 16 or more for helplessness; 11 or less for acceptance. Apart from the BDI score cut-off, they are based on 1 standard deviation (SD) from the mean, in analogy to the original Dutch version [15]. The score for risk was between 0 (no risk) and 5 (at risk in all 5 subscales).

- The "Copenhagen Multi-centre Psychosocial Infertility" Research Programme (COMPI) coping strategy scales [11]: the COMPI scales consist of 4 subscales with a total of 19 items ( 4 active-avoidance, 7 active-confronting, 3 passive-avoidance and 5 meaning-based coping items). For each coping method, we calculated the mean of the answers to obtain comparable scores. We then defined two groups, depending on the patients' use of a particular coping method. "High use" and "low use" groups were separated by the median of the scores for each coping method.

- Sociodemographic data included age, level of education, current profession, marital status, number of children, duration of wish for children, partnership, and infertility treatment, as well as current treatment and the subjective cause of infertility.

The design of the study and the selection of the questionnaires was approved by the Ethics Committee of the Medical Faculty of Heidelberg University.

\section{Data analysis}

Patients were divided into two groups: at risk/not at risk, depending on the respective results for the SCREENIVF questionnaire. The two groups were compared with women and men first evaluated separately as individual units of interest. Testing was done using ttest and chi-square test (depending on the variables' quality). This was followed by taking couples as the unit of analysis and using the APIM (actor partner interdependence model) [16]. This model ( $\vee$ Fig. 1) stipulates that one person's behavior not only affects him-/herself (actor effect) but also his/her partner (partner effect). For example, when the relationship happiness of men and women was compared based on their own description of their relationship ("two separate people" vs. "a couple"), the woman's 


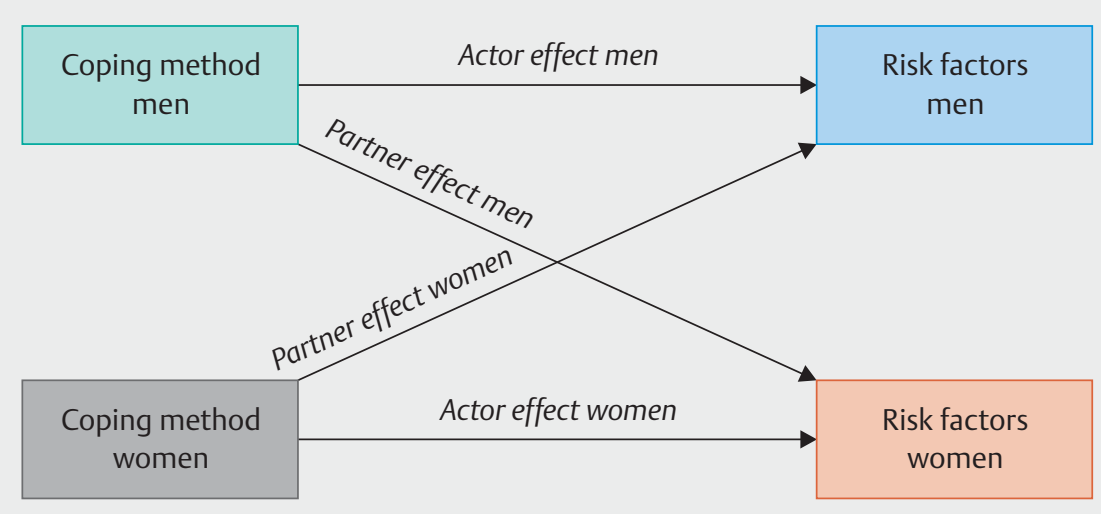

- Fig. 1 Interaction pathways in the actor partner interdependence model.

happiness depended on her own and her partner's description, while the man's happiness only depended on his own description [17].

In our APIM, the respective coping strategy was the independent variable and the risk score was the dependent variable, calculated separately for women and men. The web program APIM_MM (Actor Partner Interdependence Model with Multilevel Modeling) for distinguishable dyads by David A. Kenny (http://davidakenny.net/DyadR/DyadRweb.htm) was used to calculate the APIM. This web program also calculates effect sizes (ES) to estimate the clinical relevance of the APIM effects.

\section{Results}

\section{Sociodemographic data}

Questionnaires were handed out to 766 patients; a total of 302 patients completed the questionnaires (response rate: $39.4 \%)$. No differences with regard to language or sociodemographic data were found between patients who participated and those who did not. After excluding incomplete data, 295 patients were included in the analysis.
Mean age was 35.0 years for women and 38.2 years for men; mean duration of the wish to have a child was 4.1 years, and the mean duration of infertility treatment was 2.0 years. Overall, $53.2 \%$ of patients were found to be at risk ( $\vee$ Table 1 ), with 157 patients at risk and 138 not at risk. Calculated separately, $43.2 \%$ of men $(n=63)$ and $63.1 \%$ of women $(n=94)$ were at risk.

Level of education was divided into "higher" (university-entrance qualification [Abitur] or higher) and "lower". Overall, $59.7 \%$ of patients had a higher level of education $(60.3 \%$ of men, $59.0 \%$ of women). Educational level and the risk for depression/ anxiety did not correlate for women or men, respectively ( $\bullet$ Table 2).

With regard to the subjective cause of infertility ("lay etiology"), there were no significant differences between the two groups ("at risk" vs. "not at risk") of women and men (

\section{Coping strategies and risk factors: analysis of individuals}

When persons were analyzed as individuals, active-avoidance coping was positively correlated with risk in women $(p=0.010)$, and meaning-based coping was negatively correlated with risk in men $(p=0.025)$. There was no significant correlation between

- Table 1 Number and percentage of patients with at least one positive risk factor in at risk patients (multiple responses possible).

\begin{tabular}{|c|c|c|c|c|c|}
\hline & \multicolumn{2}{|c|}{$\begin{array}{l}\text { Men } \\
n=63(43.2 \% \text { of all men })\end{array}$} & \multicolumn{2}{|c|}{$\begin{array}{l}\text { Women } \\
n=94(63.1 \% \text { of all women })\end{array}$} & \multirow[t]{2}{*}{$\begin{array}{l}\text { Difference } \\
\text { men/women }\end{array}$} \\
\hline & $\mathbf{n}$ & $\%$ & $\mathbf{n}$ & $\%$ & \\
\hline Anxiety & 18 & 28.6 & 59 & 62.8 & $p<0.001$ \\
\hline Depression & 10 & 15.9 & 38 & 40.4 & $p=0.001$ \\
\hline Social support & 25 & 39.7 & 28 & 29.8 & NS \\
\hline Helplessness & 17 & 27.0 & 34 & 36.2 & NS \\
\hline Acceptance & 31 & 49.2 & 58 & 61,7 & NS \\
\hline
\end{tabular}


- Table 2 Sociodemographic characteristics of sub-samples.

\begin{tabular}{|c|c|c|c|c|}
\hline & \multicolumn{2}{|l|}{ At risk } & \multicolumn{2}{|l|}{ Not at risk } \\
\hline & $\begin{array}{l}\text { Men } \\
n=63(43.2 \%)\end{array}$ & $\begin{array}{l}\text { Women } \\
n=94(63.1 \%)\end{array}$ & $\begin{array}{l}\text { Men } \\
n=83(56.8 \%)\end{array}$ & $\begin{array}{l}\text { Women } \\
n=55 \\
(36.9 \%)\end{array}$ \\
\hline Mean age (years) & 38.03 & 34.60 & 38.23 & 35.69 \\
\hline Mean duration of partnership (years) & & 9.26 & & 9.27 \\
\hline Mean duration of wish for a child (years) & & 4.54 & & 3.64 \\
\hline Mean duration of treatment (years) & & 2.08 & & 1.71 \\
\hline Higher level of education & $40(63.5 \%)$ & $54(57.4 \%)$ & $48(57.8 \%)$ & $34(61.8 \%)$ \\
\hline Lower level of education & $23(36.5 \%)$ & $40(42.6 \%)$ & $35(42.2 \%)$ & $21(38.2 \%)$ \\
\hline Primary infertility & $47(74.6 \%)$ & $68(72.3 \%)$ & $58(69.9 \%)$ & $40(72.7 \%)$ \\
\hline
\end{tabular}

- Table 3 Subjective cause of infertility and risk factors.

\begin{tabular}{|c|c|c|c|c|c|c|}
\hline \multirow[t]{2}{*}{ Subjective cause } & \multicolumn{2}{|l|}{ At risk } & \multicolumn{2}{|l|}{ Not at risk } & \multicolumn{2}{|c|}{ Difference at risk/not at risk } \\
\hline & $\begin{array}{l}\text { Men } \\
n=61^{*}\end{array}$ & $\begin{array}{l}\text { Women } \\
n=94\end{array}$ & $\begin{array}{l}\text { Men } \\
n=83\end{array}$ & $\begin{array}{l}\text { Women } \\
n=55\end{array}$ & Men & Women \\
\hline No cause & $5(8.2 \%)$ & $4(4.3 \%)$ & $9(10.8 \%)$ & $5(9.1 \%)$ & NS & NS \\
\hline Cause not yet ascertained & $8(13.1 \%)$ & $7(7.4 \%)$ & $12(14.5 \%)$ & $6(10.9 \%)$ & NS & NS \\
\hline Only self & $14(23.0 \%)$ & $42(44.7 \%)$ & $21(25.3 \%)$ & 17 (30.9\%) & NS & NS \\
\hline Only partner & $15(24.6 \%)$ & $15(16.0 \%)$ & $24(28.9 \%)$ & $9(16.4 \%)$ & NS & NS \\
\hline Both partners & $19(31.1 \%)$ & $26(27.7 \%)$ & $19(22.9 \%)$ & $18(32.7 \%)$ & NS & NS \\
\hline
\end{tabular}

- Table 4 Comparison of patients at risk and not at risk with high use of a coping strategy.

\begin{tabular}{|c|c|c|c|c|}
\hline \multirow[t]{2}{*}{ Coping strategy } & \multicolumn{2}{|l|}{ At risk } & \multicolumn{2}{|l|}{ Not at risk } \\
\hline & $\begin{array}{l}\text { Men } \\
n=63^{*}\end{array}$ & $\begin{array}{l}\text { Women } \\
\mathrm{n}=94^{*}\end{array}$ & $\begin{array}{l}\text { Men } \\
n=83^{*}\end{array}$ & $\begin{array}{l}\text { Women } \\
n=55^{*}\end{array}$ \\
\hline Active-avoidance & $27(45.0 \%)$ & $51(54.3 \%)$ & $32(38.6 \%)$ & $17(32.1 \%)$ \\
\hline Active-confronting & $13(21.7 \%)$ & $39(41.5 \%)$ & $26(31.3 \%)$ & $24(46.2 \%)$ \\
\hline Passive-avoidance & $20(33.9 \%)$ & $49(52.1 \%)$ & $32(38.6 \%)$ & $21(40.4 \%)$ \\
\hline Meaning-based & $19(32.2 \%)$ & $41(45.0 \%)$ & $42(51.2 \%)$ & $24(51.1 \%)$ \\
\hline
\end{tabular}

other coping strategies and risk in either women or men $(\triangleright$ Table 4).

\section{Coping strategies and risk factors: analysis of couples}

Age at the beginning of the wish for a child (calculated as age minus duration of the wish for a child) had a significant effect on women and men as a covariate in the APIM analysis of active-confronting coping. To ensure that results were coherent, all four APIMs were calculated with patient age at the beginning of the wish for a child as a covariate.
When the couple was used as the unit of analysis, women had an actor effect of $0.398(p=0.007)$ and a partner effect of 0.312 $(p=0.003$ ) when active-avoidance coping was used as the coping strategy ( $\triangleright$ Fig. 2). Men who used active-avoidance coping had an actor effect of $0.221(p=0.040)$ and a partner effect of 0.703 $(p<0.001$, medium effect size). The difference between the two partner effects for active-avoidance coping was statistically significant ( $p=0.037)$. Women who used meaning-based coping as their coping strategy ( $\triangleright$ Fig. 3 ) had an actor effect of -0.846 $(p<0.001$, medium effect size) and a partner effect of -0.301 


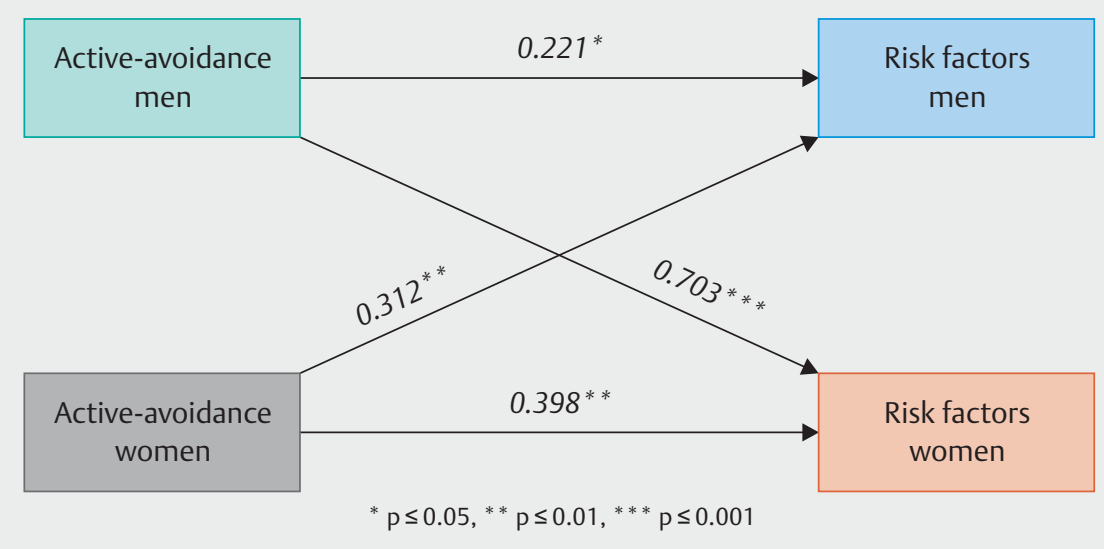

- Fig. 2 Actor partner interdependence model for active-avoidance coping.

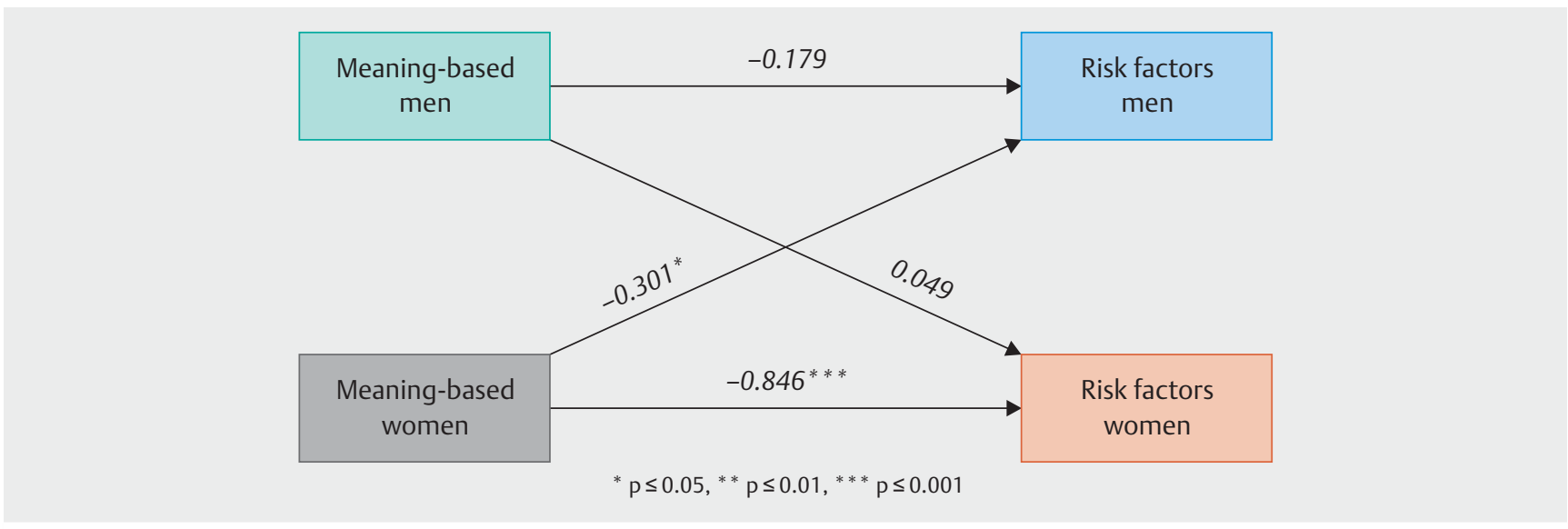

- Fig. 3 Actor partner interdependence model for meaning-based coping.

$(p=0.043)$. For meaning-based coping, the difference between the two actor effects was statistically significant $(p=0.015)$. Women who used active-confronting coping (not shown) had a partner effect of 0.426 ( $p<0.001$, small effect size); the difference between the two partner effects was statistically significant for this coping strategy $(p=0.017)$. Passive-avoidance coping was not found to be significantly correlated with either men's or women's risk (not shown).

The results for congruent versus incongruent use of the four coping strategies (concordance of the partners) are presented in

\section{- Table 5.}

In line with the APIM results, a partner's high use of activeavoidance coping was found to be correlated with the risk factor score for the actor for both women and men. This underlines the importance of the partner's coping strategy for the actor's own level of psychological distress. Men with a high use of active-confronting coping had a lower risk score, although only a small number of women used this strategy, compared to a highly congruent use of active-confronting coping. A congruent low use of meaning-based coping was correlated with higher risk factors for women, compared to women's low use and their partners' high use, again showing the importance of the partner effect (here only for women).

Our results indicate that a meaning-based coping strategy had the highest positive impact of all four strategies. The strongest actor effect (for women) in the APIM analysis was found for meaning-based copying ( $\bullet$ Fig. 3), and congruent high use of this strategy was associated with low mean risk scores for both partners, while congruent low use of meaning-based coping was associated with high risk scores for both partners ( $\bullet$ Table 5 ). In contrast, active-avoidance coping appeared to have the highest negative impact of all four coping strategies. It showed the strongest partner effect (for men) in the APIM analysis ( $\bullet$ Fig. 2), while high use of this strategy by the partner, together with low use by the actor, was found to be correlated with high mean risk scores for both women and men ( $\bullet$ Table 5). 
Table 5 Mean risk factor scores for men and women by coping strategy.

\begin{tabular}{|c|c|c|c|c|}
\hline Coping strategies by median split groups & $\begin{array}{l}\text { Active- } \\
\text { avoidance }\end{array}$ & $\begin{array}{l}\text { Active- } \\
\text { confronting }\end{array}$ & $\begin{array}{l}\text { Passive- } \\
\text { avoidance }\end{array}$ & $\begin{array}{l}\text { Meaning- } \\
\text { based }\end{array}$ \\
\hline \multicolumn{5}{|l|}{ Men (Actor) } \\
\hline - High congruence versus actor high/partner low & 1.06 vs. 0.6 & 0.94 vs. $0.26^{*}$ & 0.57 vs. 0.85 & 0.38 vs. 0.50 \\
\hline - Low congruence versus actor low/partner high & 0.40 vs. $0.79^{*}$ & 0.69 vs. 0.67 & 0.65 vs. 0.69 & 1.00 vs. 0.64 \\
\hline \multicolumn{5}{|l|}{ Women (Actor) } \\
\hline - High congruence versus actor high/partner low & 2.32 vs. 1.59 & 1.36 vs. 1.44 & 0.63 vs. 0.83 & 0.98 vs. 1.32 \\
\hline - Low congruence versus actor low/partner high & 0.77 vs. $1.64^{* *}$ & 1.56 vs. 1.43 & 1.12 vs. 1.40 & 2.04 vs. $1.06^{*}$ \\
\hline
\end{tabular}

\section{Discussion and Conclusion}

This study is based on answers from 295 patients; results from a bigger study population are needed to confirm the significance of our findings. The response rate of $39.4 \%$ could have led to a bias in the representativeness of the whole patient population. The results of the SCREENIVF showed that a high percentage (53.2\%) of fertility patients presenting to the Heidelberg University Hospital were at risk of developing depression or anxiety. Previous studies in other countries using the same questionnaire found that around $30-52 \%$ of patients were at risk $[15,18]$. Given the response rate of $39.4 \%$, it is possible that patients who were more emotionally stressed were more likely to have completed the questionnaires. These results again confirm the high stress levels of fertility patients.

Based on the data in the ESHRE guideline [6], the expectation was that women whose partner had male factor infertility would experience higher levels of anxiety than women with female factor, mixed, or unexplained infertility, but that the diagnosed type of infertility would not affect depression levels. In our sample, we did not find any significant differences between the four diagnostic groups. This could be due to the fact that our sample population also included couples whose infertility type had not yet been diagnosed as well as couples who had already had ART for some years.

In our study, active-avoidance coping was positively correlated with risk for the person herself/himself and with the risk of their partner for both women and men (men's effect on women, medium effect size). These results correspond to those of another study which used the COMPI scales [12]; in this study men and women who used active-avoidance coping as a coping strategy reported high levels of stress and had a mutually negative influence on their partner.

In our study, meaning-based coping was negatively correlated with the risk for the actors themselves (medium effect size) and their partners (small effect size) when the strategy was used by women. For men who used meaning-based coping, only chisquare analysis showed a negative correlation. These findings partly contradict the findings of a previous study based on the COMPI scales [12], in which men's use of meaning-based coping was not correlated with personal stress levels in men (or women).
But, similar to our study, women's use of meaning-based coping reduced their personal levels of stress.

In our study, women's use of active-confronting coping was associated with increased risk scores in men. These results are in contrast to the findings of a previous study [12], in which women's use of active-confronting coping was associated with slightly higher personal levels of distress. Another study, which used different questionnaires, reported conflicting results, with women who were very reticent about their feelings shown to have higher levels of distress [19].

In our study, passive-avoidance did not appear to be significantly correlated with the patient's emotional risk profile. These results differ from the results of other studies, where strong actor effects were found for both women and men in the context of this specific coping strategy [12]; in that study, high use of passiveavoidance coping was correlated with high levels of personal distress.

The results for congruent versus incongruent use of the four coping strategies are partly in line with the results of Peterson et al. [12]. Their study also found that low congruent use of activeavoidance coping was correlated with a low risk for personal stress, but this was only statistically significant for women. In contrast to our results, the study found that high congruent use of this coping strategy was associated with high personal distress for both women and men. Our study also found that low congruent use of meaning-based coping was correlated with higher levels of risk for women. In contrast to our study, Peterson et al. [12] found the same coping pattern was associated with higher levels of marital distress. These differences could be due to the use of different assessment methods for risk factors and stress levels. The subscales for cognition and social support in the SCREENIVF questionnaire use similar items to those of the COMPI fertility problem stress scales [8]; the results of our study therefore indicate significant differences in the personal stress domain.

\section{Strengths and Limitations of this Study}

A major strength of this study is that both partners of an infertile couple are investigated, using the APIM approach and the dyad as the unit of analysis. Our results correspond to the results of previous studies on active-avoidance and meaning-based coping 
strategies and confirm their findings. Results for the other two coping strategies are inconclusive, and more studies will be needed to investigate the matter further. The study results and their general applicability are limited by the low response rate and by the cross-sectional design. Most effect sizes found in this study were small.

\section{Implications for Research}

Coping strategies and risk factors for emotional maladjustment in couples with fertility problems should be investigated further. Little is known about influencing variables and resilience factors which might influence patient behavior and outcomes. Future research could look at determining the psychological covariates of coping with infertility, e.g. the quality of the couple's communication and the couple's mutual support. Our findings need to be confirmed in prospective studies to obtain a better understanding of the long-term causal effects of the described coping strategies. Only if we can determine a causality between the coping strategy and risk factors can we then evaluate the clinical benefit of the coping strategy.

\section{Implications for Practice}

If interpreted as a causality, it seems that certain coping strategies might have a protective effect, whereas others could increase the risk of developing depression or anxiety. These findings could be highly beneficial to fertility patients if they can be replicated in prospective studies. Psychological counseling could then help to increase the use of positive coping strategies such as meaningbased coping and train couples to avoid using negative coping strategies such as active-avoidance coping. Because of the importance of partner effects on psychological risks (which was borne out by our study), psychological infertility counseling should be directed at the couple rather than the individual.

\section{Acknowledgements}

We are grateful to the women and men who agreed to participate in this study.

\section{Conflict of Interest}

The authors report no conflicts of interest and have no funding sources to disclose. The authors alone are responsible for the content and writing of the paper.

\section{References}

[1] Kupka MS, D’Hooghe T, Ferraretti AP et al.; European IVF-Monitoring Consortium (EIM); European Society of Human Reproduction and Embryology (ESHRE). Assisted reproductive technology in Europe, 2011: results generated from European registers by ESHRE. Hum Reprod 2016; 31: $233-248$

[2] Schmidt L, Christensen U, Holstein BE. The social epidemiology of coping with infertility. Hum Reprod 2005; 20: 1044-1052

[3] Verhaak CM, Smeenk JM, Evers AW et al. Women's emotional adjustment to IVF: a systematic review of 25 years of research. Hum Reprod Update 2007; 13: 27-36

[4] Greil AL. Infertility and psychological distress: a critical review of the literature. Soc Sci Med 1997; 45: 1679-1704

[5] Cousineau TM, Domar AD. Psychological impact of infertility. Best Pract Res Clin Obstet Gynaecol 2007; 21: 293-308

[6] Gameiro S, Boivin J, Dancet E et al. ESHRE guideline: routine psychosocial care in infertility and medically assisted reproduction-a guide for fertility staff. Hum Reprod 2015; 30: 2476-2485

[7] Verhaak CM, Lintsen AM, Evers AW et al. Who is at risk of emotional problems and how do you know? Screening of women going for IVF treatment. Hum Reprod 2010; 25: 1234-1240

[8] Schmidt L, Holstein BE, Christensen U et al. Communication and coping as predictors of fertility problem stress: cohort study of 816 participants who did not achieve a delivery after 12 months of fertility treatment. Hum Reprod 2005; 20: 3248-3256

[9] Li J, Liu B, Li M. Coping with infertility: a transcultural perspective. Curr Opin Psychiatry 2014; 27: 320-325

[10] Rockliff HE, Lightman SL, Rhidian E et al. A systematic review of psychosocial factors associated with emotional adjustment in in vitro fertilization patients. Hum Reprod Update 2014; 20: 594-613

[11] Schmidt L. Infertility and assisted reproduction in Denmark. Epidemiology and psychosocial consequences. Dan Med Bull 2006; 53: 390-417

[12] Peterson BD, Pirritano M, Christensen $U$ et al. The impact of partner coping in couples experiencing infertility. Hum Reprod 2008; 23: 11281137

[13] Spielberger CD, Gorsuch RL, Lushene R, Vagg PR, Jacobs GA. Manual for the State-Trait Anxiety Inventory. Palo Alto, CA: Consulting Psychologists Press; 1983

[14] Beck AT, Guth D, Steer RA et al. Screening for major depression disorders in medical inpatients with the Beck Depression Inventory for Primary Care. Behav Res Ther 1997; 35: 785-791

[15] Van Dongen AJ, Kremer JA, Van Sluisveld N et al. Feasibility of screening patients for emotional risk factors before in vitro fertilization in daily clinical practice: a process evaluation. Hum Reprod 2012; 27: 3493-3501

[16] Kenny DA, Judd CM. A general procedure for the estimation of interdependence. Psychol Bull 1996; 119: 138-148

[17] Kenny DA, Ledermann T. Detecting, measuring, and testing dyadic patterns in the actor-partner interdependence model. J Fam Psychol 2010; 24: $359-366$

[18] Lopes V, Canavarro MC, Verhaak CM et al. Are patients at risk for psychological maladjustment during fertility treatment less willing to comply with treatment? Results from the Portuguese validation of the SCREENIVF. Hum Reprod 2014; 29: 293-302

[19] Pottinger AM, McKenzie C, Fredericks J et al. Gender differences in coping with infertility among couples undergoing counselling for in vitro fertilization treatment. West Indian Med J 2006; 55: 237-242 